\title{
Cranial ulceration in Atlantic salmon Salmo salar associated with Tetrahymena sp.
}

\author{
H. W. Ferguson ${ }^{1}{ }^{*}$, B. D. Hicks ${ }^{1}$, D. H. Lynn ${ }^{2}$, V. E. Ostland ${ }^{1} \&$ J. Bailey ${ }^{3}$ \\ ${ }^{1}$ Department of Pathology, University of Guelph, Guelph, Ontario N1G 2W1, Canada \\ ${ }^{2}$ Department of Zoology, University of Guelph, Ontario, Canada \\ ${ }^{3}$ Atlantic Salmon Federation, St. Andrews, New Brunswick, Canada
}

\begin{abstract}
Cranial ulceration in yearling Atlantic salmon Salmo salar L was associated with the presence of large numbers of a holotrichous ciliate tentatively identified as Tetrahymena sp. A pronounced subacute inflammation was seen in association with the invasion of head tissues. Important pathological findings included erosion of the cranium accompanied by osteoclasts, perineuritis of cranial nerves, and virtual replacement of the epithelial lining of the supraoptic canal by parasites. Whether or not the ciliates were the cause of the ulceration, treatment with formalin reduced mortality in remaining fish.
\end{abstract}

\section{INTRODUCTION}

Ulcerative dermatitides are not uncommon in farmed fish. Causes include bacteria such as Flexibacter columnaris or Aeromonas salmonicida, fungi such as Saprolegnia diclina, solar ultraviolet radiation, trauma from nets, tanks or predators, and parasites, both metazoan and protozoan. The present report documents an unusual case of dermal ulceration and underlying lesions in the head of farmed Atlantic salmon Salmo salar L. associated with the presence of numerous holotrichous ciliates identified as Tetrahymena sp.

\section{MATERIALS AND METHODS}

The fish were approximately 1 yr old. They were held in circular, roughly $8 \mathrm{~m}$ diameter concrete tanks supplied with surface water at 11 to $12^{\circ} \mathrm{C}$. The farmer reported increased mortality. Affected fish were noted to have severe fin and tail rot and bilateral discoloured patches on the top of the head (Fig. 1).

Material submitted for diagnosis included swabs from both tail and head lesions, and whole fish fixed in either $10 \%$ buffered formalin or Bouin's. The swabs were streaked and cultured aerobically on trypticase soy agar and cytophaga agar $(0.9 \%$ agar) at room

\footnotetext{
- Adressee for correspondence
}

temperature (roughly $20^{\circ} \mathrm{C}$ ). Organisms were identified by standard procedures. Scrapings from lesions were examined for the presence of protists. The fixed fish were dissected and tissues routinely processed through paraffin wax to hematoxylin and eosin or methenamine silver stained sections. Tissues examined included the grossly affected head and tail areas, heart, gills, liver, spleen, kidney and gastrointestinal tract. Included in sections through the head were brain, eye, cranial nerves, cranium and other bones of the head, plus skin, subcutis and muscle. Some tissue from the head of a Bouin's-fixed fish was removed with fine forceps and subsequently stained by Protargol silver stain as modified by Wilbert (1975). Abundance of the parasites in the tissue was estimated by counting their number in a given area and multiplying by their mean width.

\section{RESULTS}

The histopathological changes were dominated by a severe subacute inflammation affecting the tissues of the entire head except for the brain itself. Scattered in large numbers throughout the reaction were ovoid ciliated protozoan parasites which had a prominent nucleus. The skin over the cranium was thin, spongiotic and ulcerated and the dermal pigmenting cells were reduced in number. The cranium itself had large focal erosions where surface osteocytes were necrotic or 


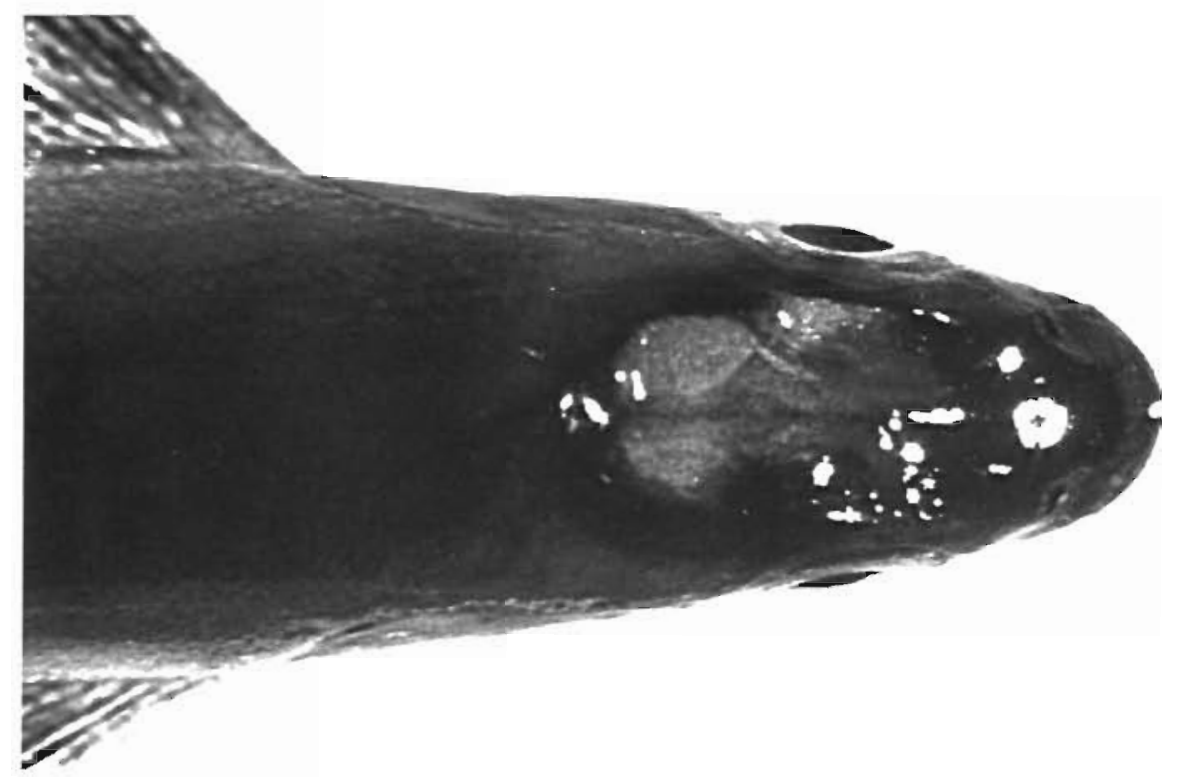

Fig. 1. Salmo salar. Young salmon with dermal depigmentation and erosion on top of head

missing entirely. Some erosions and other bone defects were accompanied by pronounced osteoclastic activity (Fig. 2).

Cranial muscles were severely affected and many fibres were degenerate or necrotic, showing loss of striation and granular degeneration. There were focal hemorrhages and, accompanying the protozoa, large numbers of infiltrating leukocytes, including lymphocytes, macrophages and plasma cells (Fig. 3). This inflammatory reaction also involved cranial nerves resulting in foci of severe perineuritis and sometimes a neuritis (Fig. 4). The ciliates were distributed in a periorbital fashion although they tended to concentrate in a retrobulbar location. The brain was for the most part uninvolved although meningeal vessels were congested and occasionally a ciliate was seen within the meninges. The epithelial lining of the supraorbital canal was almost replaced by the parasites; a mild inflammatory response accompanied this (Fig. 5).

Other lesions included acute ulcerative dermatitis of the tail with osteoclastic removal of necrotic fin rays. Protozoa were not associated with these lesions.

\section{Description of the ciliate}

The ciliates were ovoid to ellipsoid, rarely spheroid, with a pointed anterior end. However, the shape of many was distorted both by their burrowing into the tissue and by their extremely high numbers which ranged as high as $25000 \mathrm{~mm}^{-3}$ of tissue. Their dimensions $(n=30)$ were as follows: mean length $48.3 \pm 4.14$

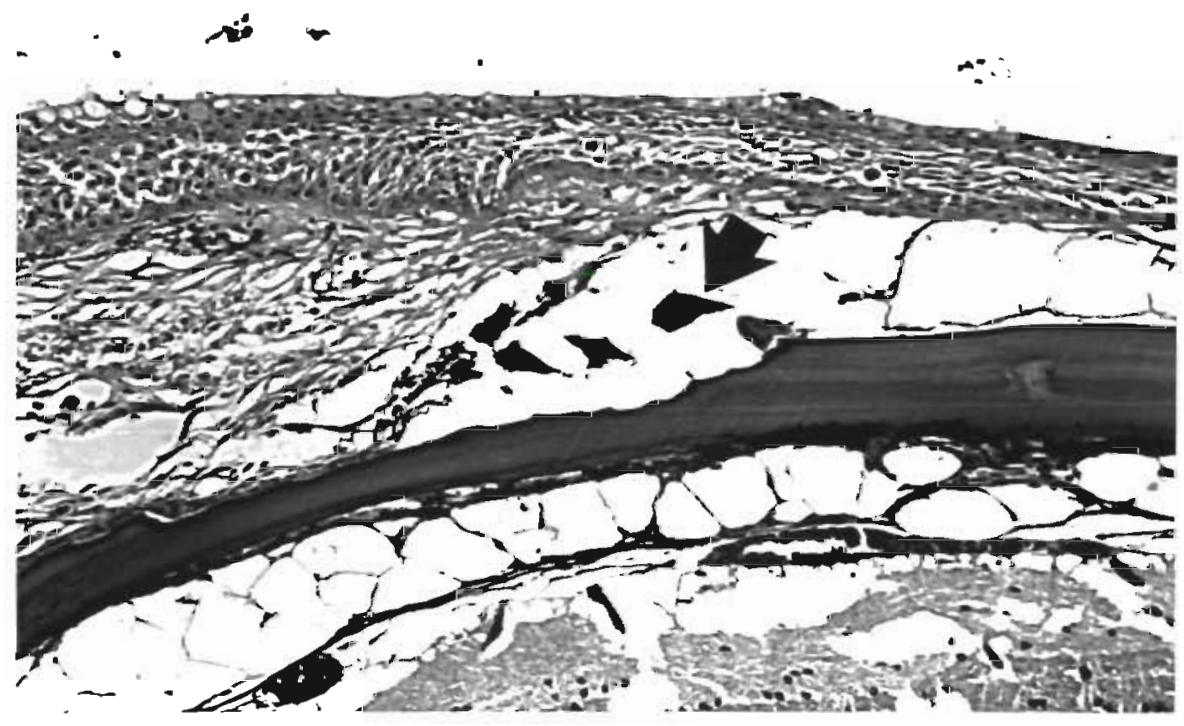

Fig. 2. Salmo salar. Section through cranium and overlying skin. Cranial bone is eroded and several osteoclasts are present (arrow). Hematoxylin and eosin 
Fig. 3. Salmo salar. Section through cranial muscle showing massive infiltration by protozoa (arrow) and accompanying inflammation. Hematoxylin and eosin

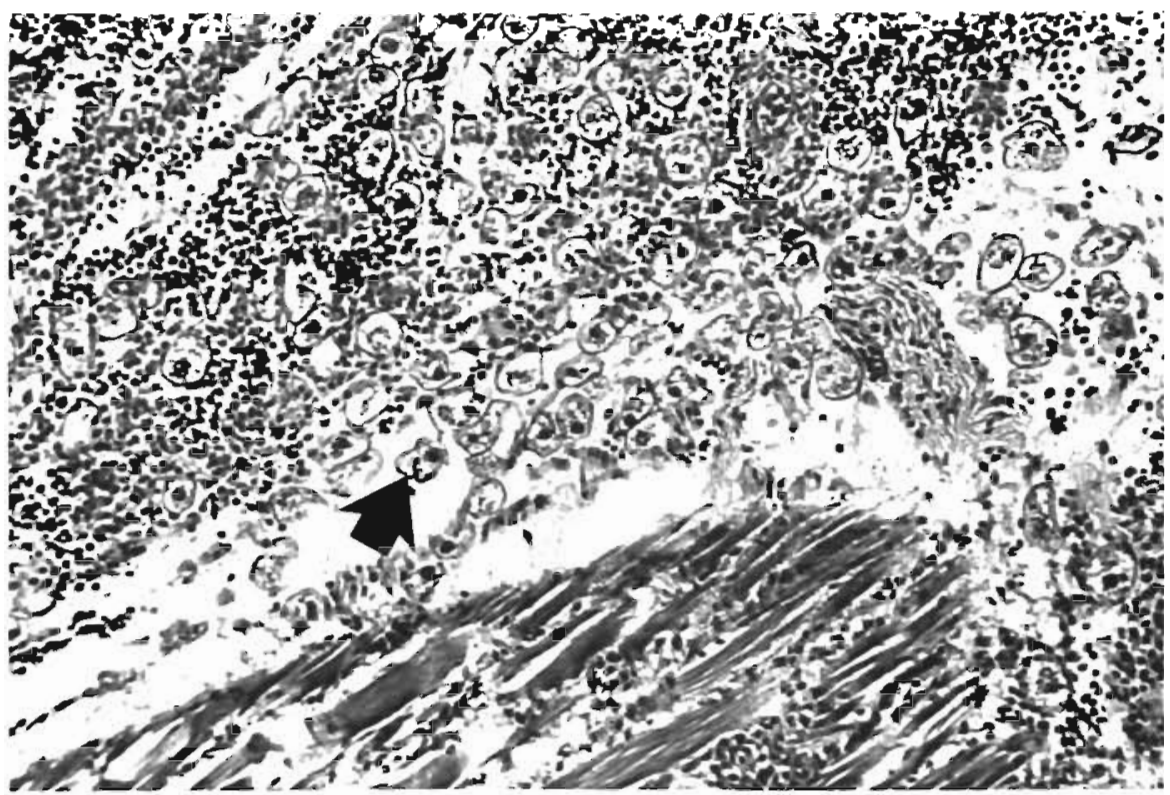

Fig. 4. Salmo salar. Cranial nerve with pronounced perineuritis; protozoa are scattered throughout the inflammatory response. Hematoxylin and eosin

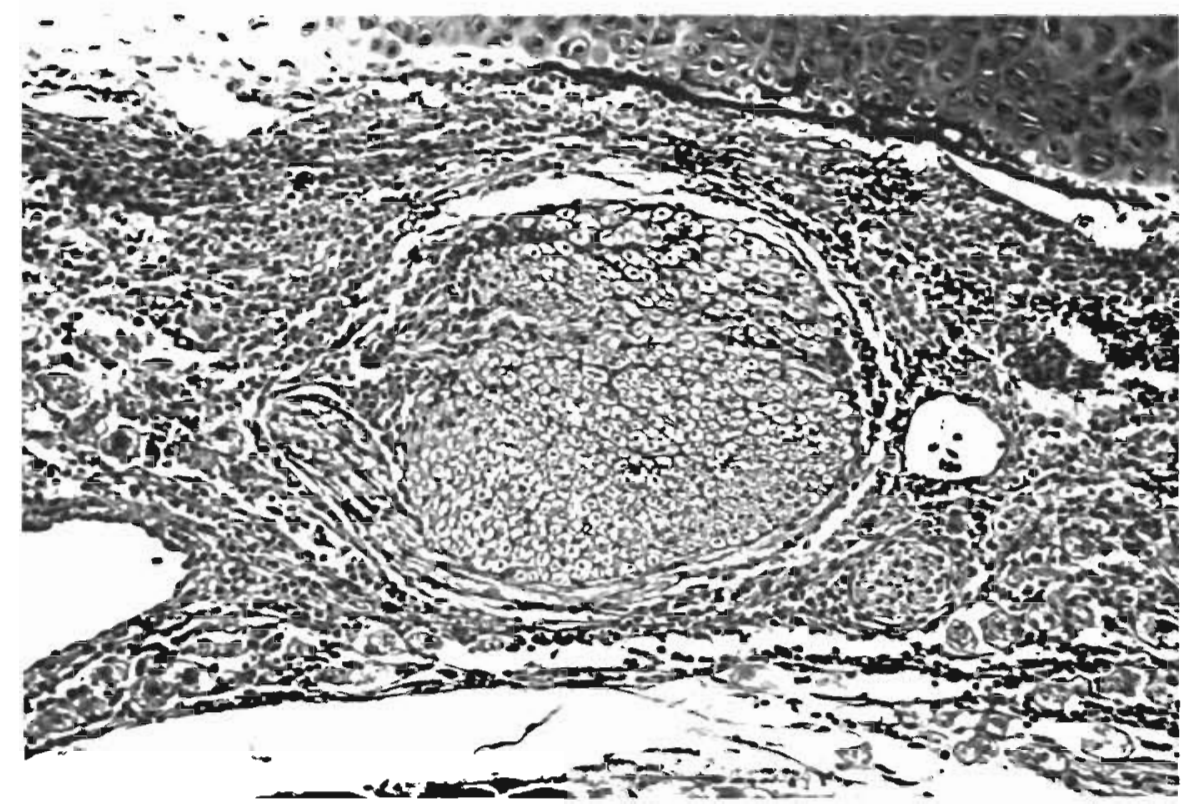

$\mu \mathrm{m}$ (range 41.7 to 60.6 ); mean width $31.0 \pm 3.4 \mu \mathrm{m}$ (range 25.9 to 37.9 ), with a mean width/length ratio of $0.64 \pm 0.075(0.52$ to 0.87$)$. The modal number of ciliary rows, of which 2 were postoral, was 34 (32 to 35; $\mathrm{n}=$ $20)$. The oral cavity had 3 membranelles on the left and an undulating membrane on the right.

Bacteriology

Pseudomonas fluorescens was recovered in small numbers from both head and tail while a few Flexibacter or Cytophaga-like organisms were recovered from the head only.

\section{DISCUSSION}

The cause of the cranial ulcers is unknown, and although it is tempting to suggest that the ciliated protozoa were responsible, the marked erosion and osteoclastic activity, combined with the bone defects, are thought to be reactions more severe than could be accounted for by the protozoa alone, and may have been the primary lesion. Moreover, we have encountered such cranial defects in other young salmonids not associated with any pathogen. Despite this, the protozoa were present in large numbers and they were probably the immediate cause of the increased mortality. 


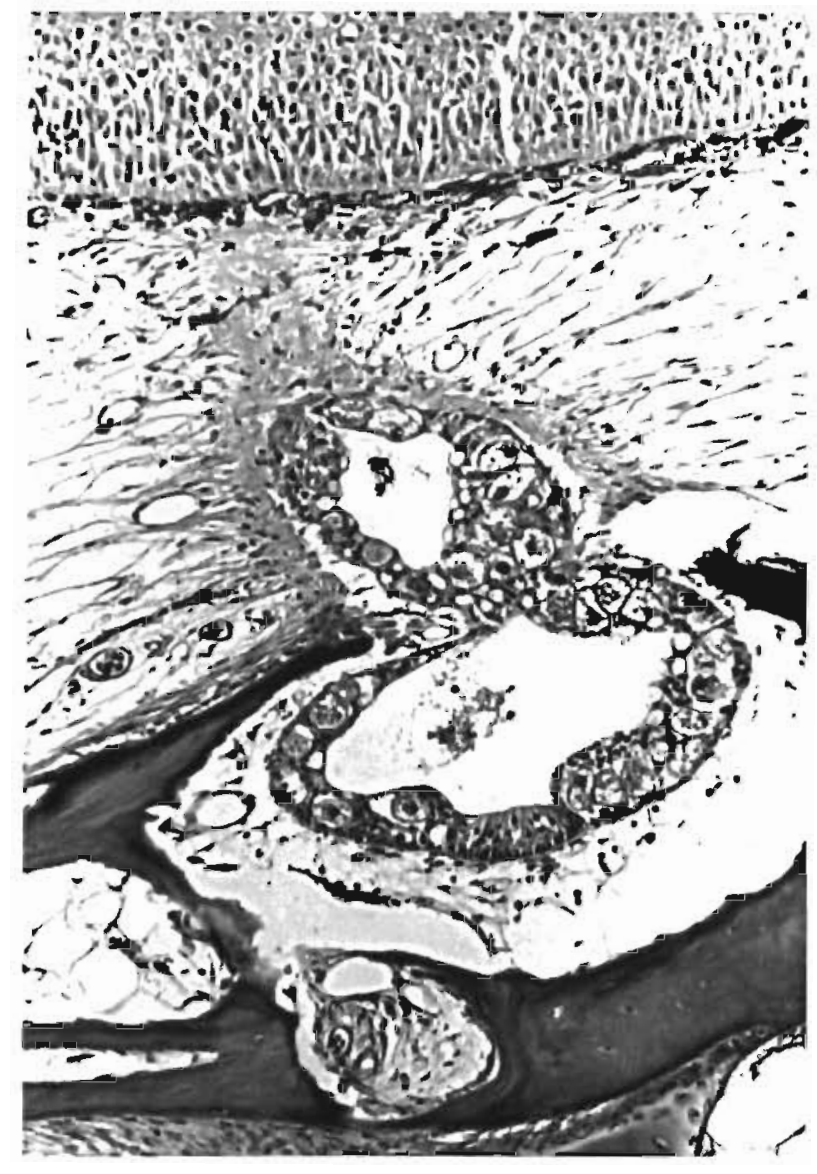

Fig. 5. Salmo salar. Section through supraoptic canal showing virtual replacement of the epithelial lining by parasites. Hematoxylin and eosin

The cell shape and arrangement of the oral structures indicate that this ciliate belongs to the genus Tetrahymena (Corliss 1973, Hoffman 1978, Small \& Lynn 1985), but it is less certain to which species it belongs. Tetrahymena corlissi is the only species that has been consistently identified in natural infections of vertebrates, including fish (Corliss 1973, Hoffman et al. 1975 and references therein) and amphibians (Corliss 1973 and references therein). The ciliates from these infected salmon fall within the size range of 30 to $90 \mu \mathrm{m}$ in length and 20 to $60 \mu \mathrm{m}$ in width but have more ciliary rows, 32 to 35 rather than 23 to 31 , and are stouter, with a width/length ratio of about $2 / 3$ rather than $1 / 3$ to $1 / 2$ for $T$. Corlissi (Thompson 1955, McArdle 1959, Corliss 1973, Hoffman et al. 1975, Lynn 1975, Hoffman 1978). Tetrahymena rostrata has a similar size range, 35 to 90 $\mu \mathrm{m}$, number of ciliary rows, 26 to 39 , and width/length ratio, $>2 / 3$, as the present ciliates from salmon (Thompson 1955, McArdle 1959, Corliss 1973, Hoffman et al. 1975, Lynn 1975, Hoffmann 1978). However, T rostrata has been reported to infect only invertebrates naturally, especially snails and slugs, and never fish or amphibians, even in laboratory tests in which strains of T. corlissi were observed to do so (Thompson 1958).

If host specificity is regarded as the more important characteristic, these ciliates from salmon should be identified as Tetrahymena corlissi whose range of ciliary rows would require revision from 23 to 31 (Hoffman 1978) to 23 to 35 to accommodate this sample. If, however, morphological features are regarded as more important, then they should be identified as $T$. rostrata whose diagnosis would require revision to include an ability to opportunistically infect fish. On the other hand, these differences could indicate the existence of a new species of Tetrahymena that parasitizes salmon. Thus, it seems premature to positively identify these ciliates to a particular species of Tetrahymena until they have been isolated, cultured, and studied in more detail

The inflammatory response was much more pronounced than was described for Tetrahymena corlissi infection of guppies Poecilia reticulatus (Hoffman et al. 1975) and than we have encountered in similar infections, also of guppies. We nevertheless ascribe the inflammatory reaction to the protozoa rather than to the bacteria, which were not apparent in sections, and which we regard as secondary. We can provide no explanation for the peculiar affinity of the ciliates for the epithelium of the supraoptic canal. Although this structure is continuous with the lateral line system, we do not believe that such a connection would have predisposed the fish to fin or tail rot, both of which are very cormmon afflictions of intensively reared salmonids. Unlike the disease in guppies, in which the organisms become widely disseminated, the ciliates in the salmon seemed to restrict themselves to the head area: vascular invasion was not a feature of the disease in these fish, and this may provide an explanation for the difference.

On the basis of the findings, the fish were treated for $1 \mathrm{~h}$ in a static bath with formalin at a concentration of 1 in 4000 , whereupon the mortality stopped.

Acknowledgements. The Fish Pathology Laboratory is partly funded by the Ontario Ministry of Agriculture and Food. D. H. Lynn acknowledges funding from N.S. E. R. C. Canada operating grant A-6544.

\section{LITERATURE CITED}

Corliss, J. O. (1973). History, taxonomy, ecology, and evolution of species of Tetrahymena. In: Elliot, A. M. (ed.) The biology of Tetrahymena, Chap. 1. Dowden, Hutchinson \& Ross, Stroudsburg, Pennsylvania, p. 1-55

Hoffman, G. L. (1978). Ciljates of freshwater fishes. In: Kreier J. P. (ed.) Parasitic Protozoa, Vol. II. Academic Press, New York, p. 583-632 
Hoffman, G. L., Landolt, M., Camper, J. E., Coats, D. W. Stokey, J. L., Burek, J. D. (1975). A disease of freshwater fishes caused by Tetrahymena corlissi Thompson, 1955, and a key for identification of holotrich ciliates of freshwater fishes. J. Parasitol. 61: 217-223

Lynn, D. H. (1975). The life cycle of the histophagous ciliate Tetrahymena corlissi Thompson, 1955. J. Protozool. 22: 188-195

McArdle, E. W. (1959). Recovery of a strain of Tetrahymena corlissi from dried moss collected in Louisiana. J. Protozool. 6 (Suppl.): 27 (Abstr. 106)
Small, E. B., Lynn, D. H. (1985). Phylum Ciliophora Doflein, 1901. In: Lee, J. J., Hutner, S. H., Bovee, E. C. (ed.) An illustrated guide to the Protozoa. Soc. Protozoologists, Lawrence, Kansas p. 393-575

Thompson, J. C., Jr. (1955). Morphology of a new species of Tetrahymena. J. Protozool. 2 (Suppl.): 12 (Abstr. 66)

Thompson, J. C. Jr (1958). Experimental infections of various animals with strains of the genus Tetrahymena. J. Protozool. 5: 203-205

Wilbert, N. (1975). Eine verbesserte Technik der Protargolimprägnation für Ciliaten. Mikrosmos 64: 171-179

Responsible Subject Editor: Dr. T. Evelyn; accepted for printing on April 23, 1987 